and other mountainous districts many other suitable places might no doubt be found.

Would it not be possible to secure funds for establishing at least one such atmospheric section on the slope of some steep hill or mountain in connection with a station or two on an adjoining level district of country?

THOMAS STEVENSCN

ON THE FYSIOLOGICAL ACTION OF $O Z O N E$

$A \mathrm{~T}$ a meeting of the Royal Society of Edinburgh on the Ist inst., a communication was read from $\mathrm{Mr}$. Dewar and Dr. $\mathrm{M}^{\prime}$ Kendrick on the physiological action of ozone. The authors, in the first place, pointed out that little was known regarding the action of this substance, except its peculiar smell and the irritating effect it had on the mucous membrane of the respiratory tract. Schönbein had shown that a mouse died in five minutes in an atmosphere highly charged with ozone; and it was this distinguished investigator who asserted that there was a relation between the quantity of ozone in the air and the prevalence of epidemic diseases. The action of ozone was therefore a subject to be elucidated; and having occasion to employ ozone in another experimental inquiry, the authors resolved to investigate the matter. The ozone was made by passing a current of dry air or oxygen from a gasometer through a narrow glass tube, bent for convenience like the letter $U$, about $3 \mathrm{ft}$. in length, and containing a platinum wire $2 \mathrm{ft}$. in length, which had been inserted into the interior of the tube, and one end of which communicated with the outside through the wall of the tube. Round the whole external surface of this $U$-shaped tube, a spiral of copper wire was coiled, and the induction current from a coil giving half-inch sparks was passed between the external copper to the internal platinum wire, so as to have the platinum wire as the negative pole in the interior of the tube. After the stream of gas was ozonised by the transmission of the induction current, it was washed by passing through a bulb-tube containing caustic potash, when air was employed, or water when pure oxygen was used, in order to eliminate any traces of nitrous and nitric acids that might have been formed. By means of the gasometer, the volume of gas passing through the tube could be ascertained.

The action of ozone was determined $\langle\mathbf{I}\rangle$ on the living animal enclosed in an atmosphere of ozonised air or of ozonised oxygen; and (2) on many of the individual living tissues of the body. Numerous experiments were made on frogs, birds, mice, white rats, rabbits, and on the authors themselves. Two experiments may be given here as llustrating the action of ozone on (I) a cold, and on (2) a warm-blooded animal.

I. On a Frog.-A large, bealthy male frog was introduced into the air chamber, through which a current of air was passing sufficient to fill a litre jar in three minutes. At the end of two minutes, the respirations were ninetysix per minute. The induction machine was then set to work so as to ozonise the air. In half a minute, the eyeballs were retracted, so as to appear deeply sunk in the orbits, and the eyelids were closed; the respirations were now eight per minute. At the end of six minutes, the animal was motionless, and there were no respiratory movements. Pure air was then introduced. In half a minute, there was a slight respiratory movement, and in eight minutes there were eighty.five respirations per minute. At the end of other twelve minutes, ozone was again turned on, with the same result. A frog will survive in a dormant condition in an atmosphere of ozonised air for several hours. In one case, the animal died. The heart was found still pulsating. It was full of dark blood. The lungs were slightly congested. The blood was venous throughout the whole body. In ozonised oxygen the effects were, on the whole, the same as in ozonised air, with this difference, that in ozonised oxygen the respiratory movements were not affected so quickly, and were never completely arrested.

2. On a bite Mouse.-A full grown and apparently healthy white mouse was introduced into a vessel through which a stream of air was passing at the rate of eight cubic inches per minute. Five minutes thereafter, the animal was evidently at ease, and the respirations were over 100 per minute. The air was then ozonised. One minute after, the respirations were slower, but the number could not be ascertained owing to the animal moving uneasily about. In four minutes from the time of the introduction of the ozone, the respirations were thirty-two in a minute. The mouse now rested quietly, occasionally yawned, and, when touched by a wire, moved,--but always so as to remove its nose from the stream of ozonised air. At the end of fifteen minutes, the animal had slight convulsive attacks, which increased in severity until it died-nineteen minutes after the introduction of the ozone. The post-mortem appearances were great venous congestion in all parts of the body. The heart pulsated for several minutes after systemic death. In ozonised oxygen, death was delayed for a much longer period. Instead of dying at the end of fifteen or twenty minutes, as happened to mice in ozonised air, they lived for forty or sixty minutes. It is noteworthy that even after death in ozonised oxygen; the blood was found to be in a venous condition.

On breathing an atmosphere of ozonised air themselves, the authors experienced the following effects:-a suffocating feeling in the chest; a tendency to breathe slowly; irritation of the fauces and glottis; a tingling of the skin of the face and conjunctivæe. The pulse became feebler. The inhalation was continued for eight minutes, when they were obliged to desist; and the experiment was followed by violent irritating cough and sneezing, and for five or six hours thereafter by a sensation of rawness in the throat and air-passages.

The general result of the inquiry may be briefly stated as follows :-

I. The inhalation of an atmosphere highly charged with ozone diminishes the number of respirations per minute.

2. The cardiac pulsations are reduced in strength and this organ is found beating feebly after systemic death.

3. The blood is found after death to be in a venous condition, both in those cases of death in an atmosphere of ozonised air and of ozonised oxygen.

4. The inhalation of an ozonised atmosphere is followed by a lowering of the temperature of the body to the extent of at least $3^{\circ}$ to $5^{\circ}$. C.

5. The inhalation of ozone does not exercise any appreciable action on the capillary circulation, as seen in the web of the frog's foot under the microscope (200 diameters).

6. In the bodies of frogs killed in an ozonised atmosphere, the reflex activity of the spinal cord is not appreciably affected.

7. By means of a myographion, the work done (in gramme-millimetres) by the gastronemius muscles of frogs subject to the action of ozone was noted. The muscles were stimulated by a single opening or closing induction shock produced by Du-Bois-Reymond's apparatus and a Daniell's cell. The result was that the contractility and work-power of the muscle were found to be unaffected.

8. Ozone has an action on the coloured and colourless corpuscles of human blood and of frog's blood resembling that produced by a weak acid; and in the case of the coloured corpuscles of the frog like that of a stream of carbonic acid. The corpuscles of animals killed in an ozonised atmosphere are normal in appearance.

9. Ciliary action is not affected by a stream of ozonised air or oxygen, provided there is a considerable amount of 
Huid covering the cilia; but if the layer of huid be very thin, the cilia are readily destroyed.

In conclusion, the authors stated that it would be premature, at this stage of the inquiry (which opened up many points of interest in the physiology of respiration), to generalise between physiological action and the physical and chemical properties of ozone; but they pointed out the fact that the density of ozone $\left(\mathrm{O}_{3}=24\right)$ is slightly greater than than that of carbonic acid $\left(\mathrm{CO}_{2}=22\right) ;$ and that although the chemical activity of the substance is much increased, yet, when inhaled into the lungs, it must retard greatly the rate of diffusion of carbonic acid from the blood, which accounts (from the accumulation of $\mathrm{CO}_{2}$ ) for the venous character of that fluid after death. From this point of view, destruction of life by ozone (with the exception of its irritant action) resembles that caused by an atmosphere surcharged with carbonic acid. This has been found to be the case more especially as regards the diminished number of respirations per minute, and the appearance of the blood after death. If, however, the analogy were perfect, the inhalation of an atmosphere of ozonised oxygen would not have produced death, because it is now well known, as shown by Regnault and Reiset, ${ }^{*}$ that animals can live in an atmosphere containing a large per-centage of carbonic acid, provided there is an excess of oxyger present. The amount of oxygen in these experiments converted into ozone certainly never exceeded ten per cent. But the authors have observed that an animal lives only a somewhat longer time in ozonised oxygen than in ozonised air; and they are thus induced to regard ozone as having some specific action on the blood that their future experiments may elucidate. They are now prosecuting a series of researches $(a)$ on the action of smaller percentages of ozone; $(b)$ on the action of ozone on noxious gases and effuvia; and $(c)$ on any therapeutical or hygienic infiuences it may have on the origin and treatment of zymotic diseases.

\section{THE ATMOSPHERIC TELEGRAPH†}

\section{II.}

A VERY common question with visitors who witness the road how do you manage to disengage them? To answer this question we shall notice in detail the various

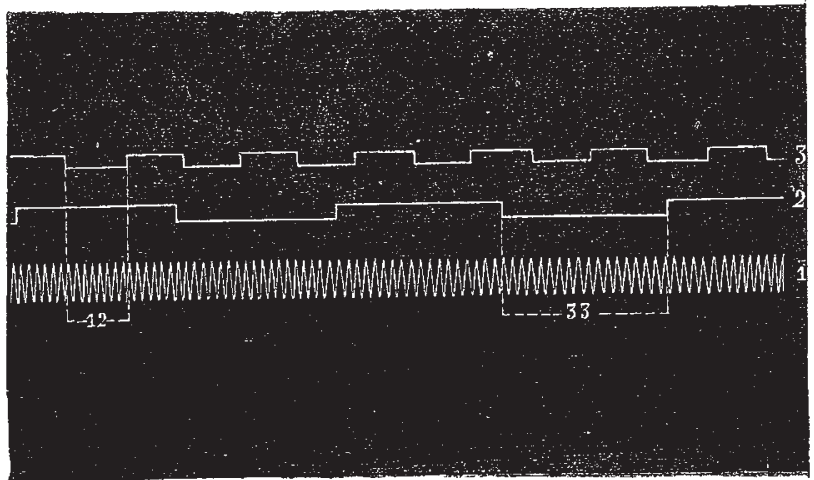

FIG. 3. - Diagram of the Chronograph. r. Line of the electric trentblent 2. Line of the seconds' pendulum. 3. Kine of the m?mbrane

means employed in transmission, and thus we shall classify the derangements.

Let us commence with the tubes. These may cause an obstruction by a defect of the interior polisb, by projecting joints, or by the escape of air through these joints. In the Paris system, however, precautions have been * "Air and Rain," by Dr. Angus Smith, p. 18z. (London, $\mathbf{x} 87_{2}$.)
$\dagger$ Continued from p. 66 . taken against these three sorts of danger. The clegree of polish is sufficiently perfect, being obrained without hammering, by pushing the tube along a mandril before it becomes completely cooled. The joints represented in Fig. 2 (p. 66), give an almost mathematical continuity to the interior surface, and they are rendered air-tight by means of India-rubber fittings. In this direction, then, there is little risk of damage and the consequent stoppage of the trains. In fact, since I 866 there has not been a single accident caused by any defect in the tubes, and the experiment is made upon a length of twenty kilometres of pipes so constructed that joints occur every five metres.

The derangements arising from the machinery for compressing the air are not of a special character, and need not be particularised here. There remain the boxes. Numerous types were tried before the system of the two cases in tin and leather, which can be hermetically closed and are easily opened; from its simplicity this method has been adopted. Nevertheless it does sometimes happen that the boxes open during the journey; how this is caused is not easy to explain in each particular case. Sometimes the collarette of the piston is in a bad condition, and the air divides the train; the cases are separated, and the despatches are scattered in the tube. At other times wrinkles are formed in the envelope of leather, the effect of which is to wedge the train so firmly that it is impossible to make it move. Another form of derangement is when the piston breaks and the pieces are lodged between the boxes and the tube. It is scarcely possible to exhaust the series of accidents of this nature; the mean number of derangements in the working of the system during the year is eight, and it is rare to find the same cause occurring twice. When accidents do occur, it is necessary to make all haste to relieve the train.

Often alternate manœuvres with compressed and rarified air removes the obstruction; at Berlin, for the same purpose, M. Siemens employs water with which he forcibly inundates the tube. The great thing is to extricate the train without having to take the line to pieces. When such means fail it is necessary to have recourse to the operation of excavation; and the recessity will be evident of a preliminary and sufficiently exact determination of the place of derangement. 'The first means is indicated by the method on which the system is worked. There is at hand a reservoir of compressed air of a certain pressure; if this air is partly distributed in the section of the tube comprised between the reservoir and the obstacle, the new pressure is in a known ratio to the original pressure. In a word, Mariotte's law, which regulates the ratios of the pressures and volumes of the same mass of gas in two different circumstances, furrishes the means of finding one of the elements, volume, whers we know the three others, two pressures and one volume.

M. Siemens pelers to measure the quantity of water which it is necessary to distribute in order to flood the line as far as the obstacle; the accuracy ought to be very great, but it must be acknowledged that the process, in spite of its apparent simplicity, has a somewhat primitive aspect. It is not difficult to understand how this great mass of water is introduced, but it is very difficult to conceive that it can easily remove the obstacle.

We may speak, finally, of an indirect means which is illustrated in Fig. 4. The reader knows that when a concussion is produced at the end of a tube filled with air, this concussion is propagated in the air of the tube at a speed of 330 metres per second. When the concussion encounters an obstacle, it is reflected and returns to the point of its origin at the same rate of 330 metres per second. If then the time is noted which elapses between the departure and the return, the period thus obtained cor responds to the passage of the concussion along a distance equal to double the distance of the obstacle; from an observation of the time, the distance can be easily calculatod. 